\title{
Clinical Trial Subject Unique Identifier
}

National Cancer Institute

\section{Source}

National Cancer Institute. Clinical Trial Subject Unique Identifier. NCI Thesaurus. Code C70731.

A unique identifier assigned to each clinical trial subject to protect the subject's identity and used in lieu of the subject's name when the investigator reports adverse events and/or other trial-related data (ICH Guidelines). 